\title{
Gas-phase hydrodeoxygenation of benzaldehyde, benzyl alcohol, phenyl acetate and anisole over precious metal catalysts
}

Celeste González, Pablo Marín, Fernando V. Díez, Salvador Ordoñez*

Department of Chemical and Environmental Engineering, University of Oviedo, Facultad de Química, Julián Clavería 8, Oviedo 33006, SPAIN

*Phone: 34-985 103 437, FAX: $34-985103$ 434, e-mail: sordonez@uniovi.es 


\section{Captions to figures}

Figure S1 Temperature Programmed Oxidation (TPO) tests of the aged catalysts for the hydrodeoxygenation of benzaldehyde $(\square / \square)$ and benzyl alcohol $(\diamond / \diamond)$ : a) $\mathrm{Pt} / \mathrm{Al}_{2} \mathrm{O}_{3}$ and b) $\mathrm{Pd} / \mathrm{Al}_{2} \mathrm{O}_{3}$.

Figure S2 Temperature Programmed Oxidation (TPO) tests of the aged catalysts for the hydrodeoxygenation of phenyl acetate $(\Delta / \mathbf{\Delta})$ and anisole $(\bullet)$ : a) $\mathrm{Pt} / \mathrm{Al}_{2} \mathrm{O}_{3}$ and $\mathrm{b}$ ) $\mathrm{Pd} / \mathrm{Al}_{2} \mathrm{O}_{3}$. 
Figure S1

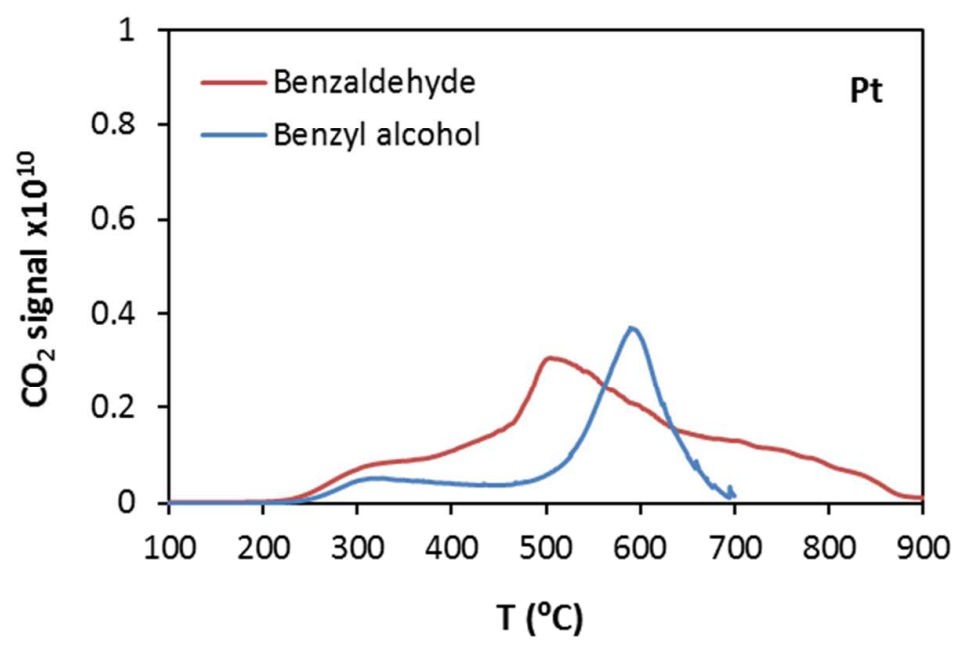

a)

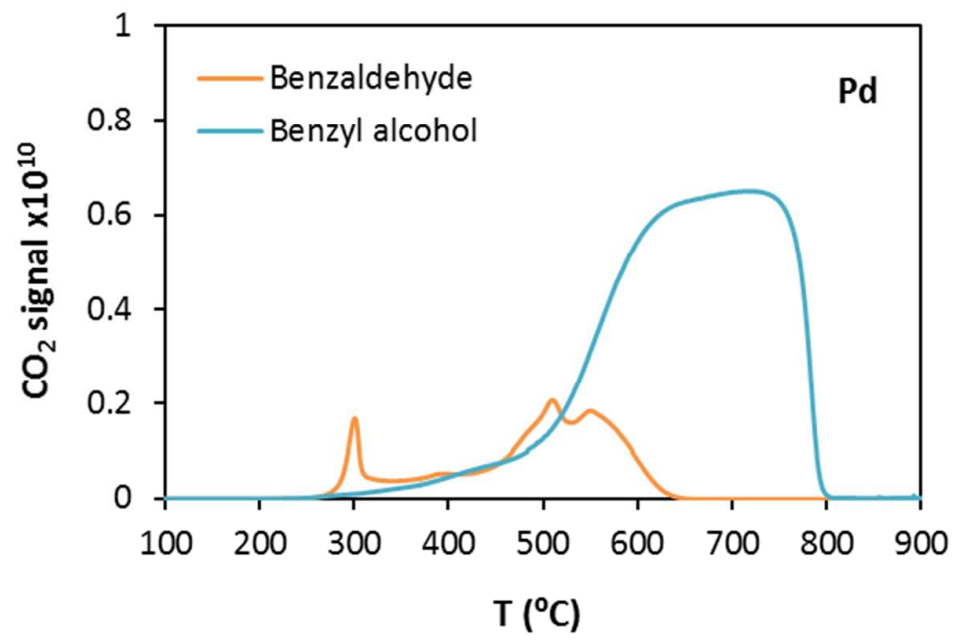

b) 
Figure S2

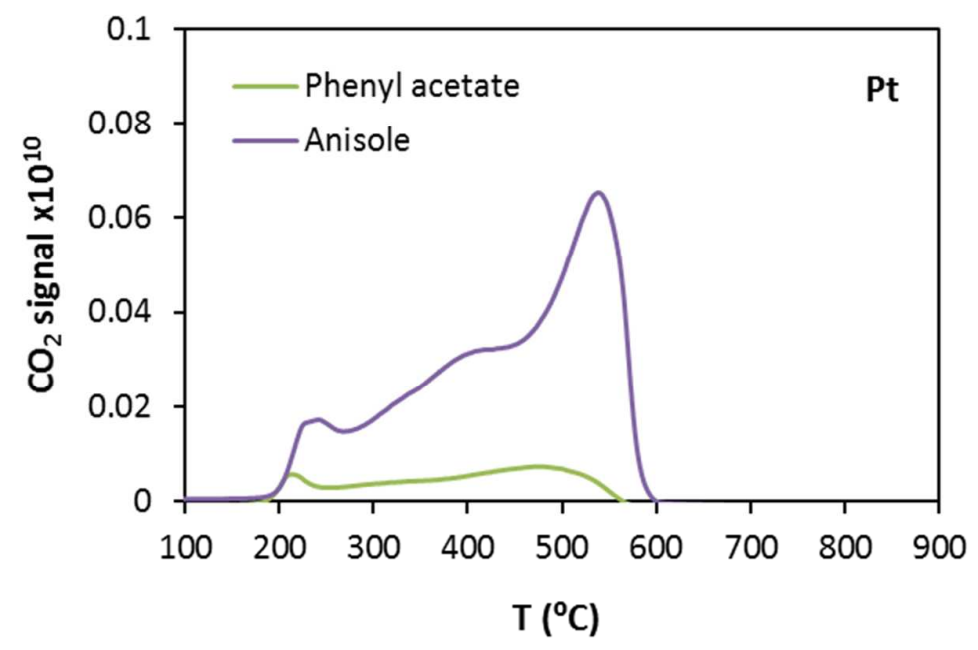

a)

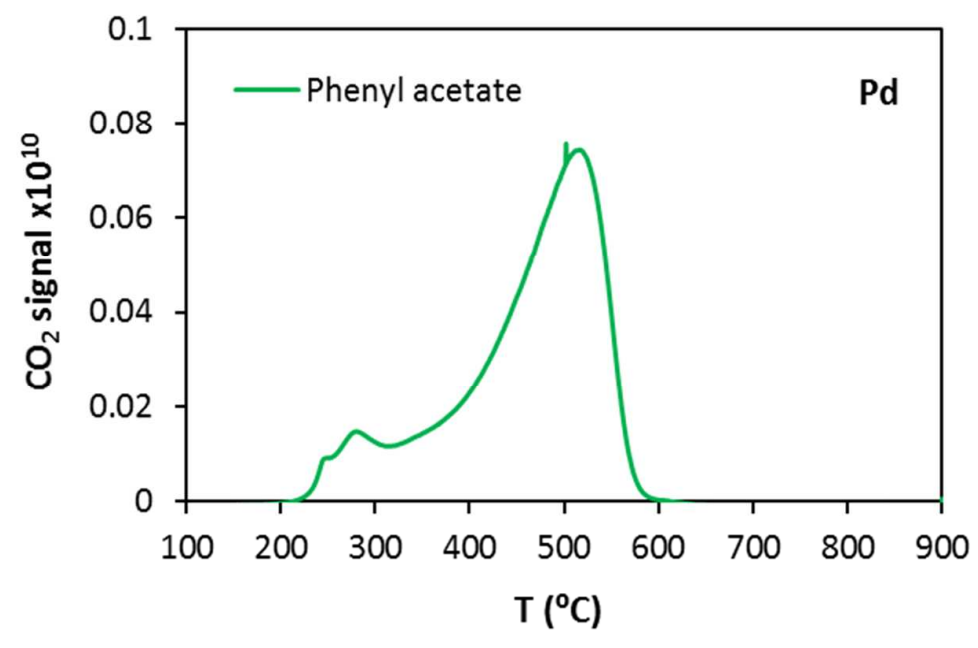

b) 